\title{
The Effects of Health Expenditure on Health Outcomes Based on the Classification of Public Health Expenditure: A Panel Data Approach
}

\author{
Aziz Rezapour ${ }^{1}$, Abdoreza Mousavi ${ }^{2,{ }^{*}}$, Farhad Lotfi ${ }^{3}$, Maryam Soleimani Movahed ${ }^{2}$ and Samira \\ Alipour $^{2}$ \\ ${ }^{1}$ Health Management and Economics Research Center, Iran University of Medical Sciences, Tehran, Iran \\ ${ }^{2}$ Department of Health Economics, School of Health Management and Information Sciences, Iran University of Medical Sciences, Tehran, Iran \\ ${ }^{3}$ Health Human Resources Research Center, School of Management and Information Sciences, Shiraz University of Medical Sciences, Shiraz, Iran \\ "Corresponding author: Department of Health Economics, School of Health Management and Information Sciences, Iran University of Medical Sciences, Tehran, Iran. Email: \\ mousaviabdoreza_1371@yahoo.com
}

Received 2018 December 31; Revised 2019 July 05; Accepted 2019 July 22.

\begin{abstract}
Background: Health expenditure is among the factors affecting the improvement of a society's health status. Hence, recognizing the effects of public and private health expenditure on health status is vital for making the required decisions.

Objectives: This study aimed to compare the effects of different levels of health expenditure on life expectancy, infant mortality rate, and under-five mortality rate as health indicators.

Methods: The current study is an analytical research, which was conducted based on a cross-sectional and annual time series data. In this study the effects of private and public health expenditure on health indicators from 2000 to 2015 were investigated. The selected countries had the middle or high-income level and were classified into three groups based on the public health expenditure rate and k-mean method. The required data were collected from the World Bank site and for estimating the model, panel data regression models were used.

Results: Public health expenditure had a significant effect on health indicators in all groups, thus, an increase in public health expenditure led to increasing life expectancy and decrease infant and under-five mortality rate in all groups. Also, the group with the highest share of health expenditure had a greater impact on life expectancy and infant mortality, however, in regards to the underfive mortality rate, it was contrary. The effect of private health expenditure was different and in most cases it had no significant effect.

Conclusions: The findings of this study indicated that public health expenditure is more effective than the private health expenditure and it also improved health status by creating positive external effects. Therefore, the governments must provide enough required financial resources for improving health status.
\end{abstract}

Keywords: Public Health Expenditure, Private Health Expenditure, Life Expectancy, Mortality Rate

\section{Background}

Health is a multidimensional concept that moves beyond the social, economic, cultural, and national relations; it is also known as an indicator for social and economic improvement and development (1). Generally, life expectancy and mortality rate for different groups with different age and gender are used as proxies of health status and for determining the society's health level (2-4). In addition, life expectancy was used as the indicator of the health system efficiency, economic development, and human well-being (5). Many countries consider health care as basic rights, which is because such cares will improve the individual's quality of life (6). Due to the significant role of health in improving the individual's welfare, the health policymakers are attempting to find available and efficient mechanisms in order to improve society's health status $(3,7)$.

That's why, during the last decade, the literature of health economy has experienced some improvements and the focus is mostly on health expenditure, financial stability, and the relationships between health expenditure and their outputs $(8,9)$. During the last decades, many countries have experienced improvements in health status by increasing life expectancy and decreasing children's mortality rate (10). Economic conditions play a significant role in determining society's health (11). Generally, rich countries have a more favorable health status and allocate more money in this scope. However, spending too much money, after a while, may not cause an increase in life expectancy of the people (12). 
Moreover, improvement in health status and life expectancy is not a phenomenon happening overnight, however, it takes time and needs detection of main factors playing roles in such issues (3). To improve health status, policymakers should focus on factors such as private and public health expenditures that lie in the health care system (13). Understanding the effective factors on the public health care expenditure is key to designing the practical policies in the scope of the health system (14). Therefore, detecting the effective rate of public and private health expenditure is of considerable significance (15).

Various studies on the relationships between health expenditure and their outputs had different and contradictory results $(5,16,17)$; even the studies conducted in developed and industrialized countries (18). Therefore, higher expenditure in developed countries is not always followed by improvements in health outputs (19). In spite of various studies carried out on the relationship between health policies and their outputs (19), and because of the different effects of public and private health expenditure on health indicator (13) for having a correct view of this different impact, more studies are needed (15).

\section{Objectives}

Therefore, the current paper aims to investigate the public and private health expenditure and their effects on health indicators in countries with moderate and highincome level from 2000 to 2015. Since these countries are classified by k-mean and based on their public health expenditure, it is possible to compare different levels of health expenditure and their outputs for each group of countries.

\section{Methods}

The current study is analytical research which was conducted based on cross-sectional and annual time series data. In this study the effects of private and public health expenditure on health indicators from 2000 to 2015 were investigated. According to a study conducted by Linden and Ray, in this study, the countries were classified into three groups by k-mean method based on the public health expenditure rate from national income. The countries were classified according to the level of public health, because public health expenditure is a political variable and private health expenditure is a non-political variable (15). First, 105 countries with a moderate and high-level income, based on the World Bank report and classification, were selected. Second, based on the average of their public health expenditure from 2000 to 2015, the countries were classified into three groups. Then, it was possible to investigate if different amounts of public and private health expenditure have various effects on health indicators.
After classifying countries into three groups, according to health expenditures, for each group separately, three health indicators were estimated separately. The required data were collected from the World Bank site.

To determinate the effects of public and private health expenditure on health indicators we used the model of Novignon et al. study, which is shown below (20):

$H S_{i t}=F\left(P u H E_{i t}, \operatorname{Pr} H E_{i t}, Y_{i t}, \operatorname{Pop} 1_{i t}, \operatorname{Pop} 2_{i t}, P o p 3_{i t}\right)$

Where HS represents health outcomes (life expectancy at birth, infant mortality rate, and under-five mortality rate), PuHE $\mathrm{it}_{\mathrm{it}}$ and $\mathrm{PrHE}_{\mathrm{it}}$ are public and private health expenditure as percentage of real national income, $Y$ is per capita real income, Pop 1, 2, and 3 represents a percentage of total population age groups of under 14, $15-64$, and above 65 years in country $i$ in period $t$.

$\mathrm{Y}$ acts as a control variable for the demand for health services and other economic factors. Variables Pop 1, 2, and 3 were included to control the different country demographic structures. Therefore, we used the Equation 2:

$$
\begin{aligned}
\ln H S_{i t}= & \alpha_{0}+\alpha_{1} \ln P u H E_{i t}+\alpha_{2} \ln \operatorname{Pr} H E_{i t}+\alpha_{3} \ln Y_{i t} \\
& +\alpha_{4} \ln \operatorname{Pop}_{i t}+\alpha_{5} \ln \operatorname{Pop} 2_{i t}+\alpha_{6} \ln \operatorname{Pop} 3_{i t}+u_{i t}
\end{aligned}
$$

That $\alpha_{0}$ is time invariant and the captures countryspecific effect that was not included in the model and $\varepsilon_{\text {it }}$ is the error term (20).

Private health expenditure includes out-of-pocket spending, private insurance, charitable donations, and direct service payments by private corporations. Public health expenditure consists of recurrent and capital spending from government budgets, external borrowings and grants, and social health insurance funds (21). Due to the difference in the income and expenditure between each country, to standardize and provide comparisons, the percentage of health expenditure were used as two separate variables.

The model's estimation was done by STATA software and Panel data regression models. For checking the variables stationary, panel unit root test was used. To make sure that there is a long-term relationship between variables and to prevent spurious regression, co-integration test was conducted. In panel data, the most common unit root tests and co-integration tests are Levin, Lin, and Chu unit root test and Pedroni co-integration test (22). In the next step, for determining pool or panel of models F-Limer was used. Then, Hausman test was used to select the appropriate model between the fixed and random effects models. 


\section{Results}

Results of countries classification based on the average of their public health expenditure through k-mean in SPSS software are given in Table 1 . It is clear that the first group has the lowest rate and the third group has the highest rate in public health expenditure.

\begin{tabular}{lccc}
\hline Table 1. K-Means Clustering & & & \\
\hline Group & Group 1 & Group 2 & Group 3 \\
\hline Share of public health expenditure & 2.21 & 4.40 & 7.02 \\
\hline
\end{tabular}

\subsection{Descriptive Statistics}

Descriptive statistics of the main variables are reported in Table 2. As shown in Table 2, the third group has better health status than the other groups. The average of public health expenditure in the third group is higher. However, the average of private health expenditure in the second group is the highest and in the third group is the lowest one. That is to say, countries allocating higher share of their income to public health expenditure have better health status.

\begin{tabular}{|lccc|}
\hline Table 2. Descriptive Statistics & & & \\
\hline Variables & Mean \pm SD & Min & Max \\
\hline & Group 1 & & \\
\hline Life expectancy & $70.91 \pm 5.17$ & 51.75 & 82.74 \\
\hline Infant mortality rate & $26.17 \pm 17.88$ & 2.10 & 87.90 \\
\hline Under 5 mortality rate & $33.26 \pm 25.56$ & 2.70 & 113.80 \\
\hline Health expenditure (public) & $2.21 \pm 0.83$ & 0.18 & 5.01 \\
\hline Health expenditure (private) & $2.52 \pm 1.41$ & 0.08 & 7.92 \\
\hline & Group 2 & & \\
\hline Life expectancy & $73.56 \pm 3.32$ & 65.05 & 82.92 \\
\hline Infant mortality rate & $13.28 \pm 7.26$ & 1.70 & 33.90 \\
\hline Under 5 mortality rate & $15.56 \pm 8.52$ & 2.30 & 39.70 \\
\hline Health expenditure (public) & $4.47 \pm 1.08$ & 1.75 & 8.23 \\
\hline Health expenditure (private) & $2.56 \pm 1.14$ & 0.58 & 6.46 \\
\hline Life expectancy & Group 3 & & \\
\hline Infant mortality rate & $79.52 \pm 2.22$ & 69.94 & 83.79 \\
\hline Under 5 mortality rate & $4.68 \pm 3.47$ & 1.90 & 35.10 \\
\hline Health expenditure (public) & $5.62 \pm 4.19$ & 2.40 & 43.80 \\
\hline Health expenditure (private) & $6.95 \pm 1.23$ & 3.57 & 10.76 \\
\hline & $2.40 \pm 1.48$ & 0.61 & 8.98 \\
\hline & & & \\
\hline & & & \\
\hline
\end{tabular}

\subsection{Econometrics Results}

Results of the panel unit root test indicated that some variables are non-stationarity, however, they became stationarity with first order difference. In order to prevent spurious regression and to be sure that there is a longterm relationship between variables, the co-integration test was done. Results of Pedroni co-integration test confirmed the long-term relationship between the variables in all models. For selecting the appropriate estimation, FLimer and Husman tests were used, results are shown in Table 3. Therefore, for the first model in the first group, GLS- random effects method was suitable and for the other models, GLS- fixed effects method was appropriate.

For each group and model, estimations were done separately. Results were reported at the level of $5 \%$ and were interpreted just for the main variables.

As shown in Table 4, in group 1 (countries with the lowest rate of public health expenditure) public health expenditure had a significant effect on all health indicators, therefore, health expenditure increased life expectancy and decreased the mortality rate. Moreover, private health expenditure had no significant effect on life expectancy and under-five mortality rate, however, it significantly decreased infant mortality rate.

According to the results given in Table 5, public health expenditure in the second group had a significant effect on all health indicators, which increased life expectancy and decreased mortality rate. In addition, private health expenditure had a significant effect on life expectancy and infant mortality rate, as well as increased them.

Table 6 shows that public health expenditure in the third group (countries with the highest rate of public health expenditure) had a significant effect on health indicators, such as increased life expectancy and decreased mortality rate. However, private health expenditure did not have a significant effect on life expectancy and infant mortality rate, however, it increased significantly underfive mortality rate.

\section{Discussion}

The current study investigated the effects of private and public health expenditure on health indicators; life expectancy, infants, and under-five mortality rate in countries with moderate and high-level income. Results revealed that public health expenditure had a significant effect on health indicators in all groups and improved health status. However, private health expenditure had some positive, negative, and contradictory results. Public health expenditure is a political variable and private health expenditure is a non-political variable $(15,23)$, therefore, it had a heterogeneous effect on health status.

The highest effect of public health expenditure on life expectancy were observed in countries with the highest 


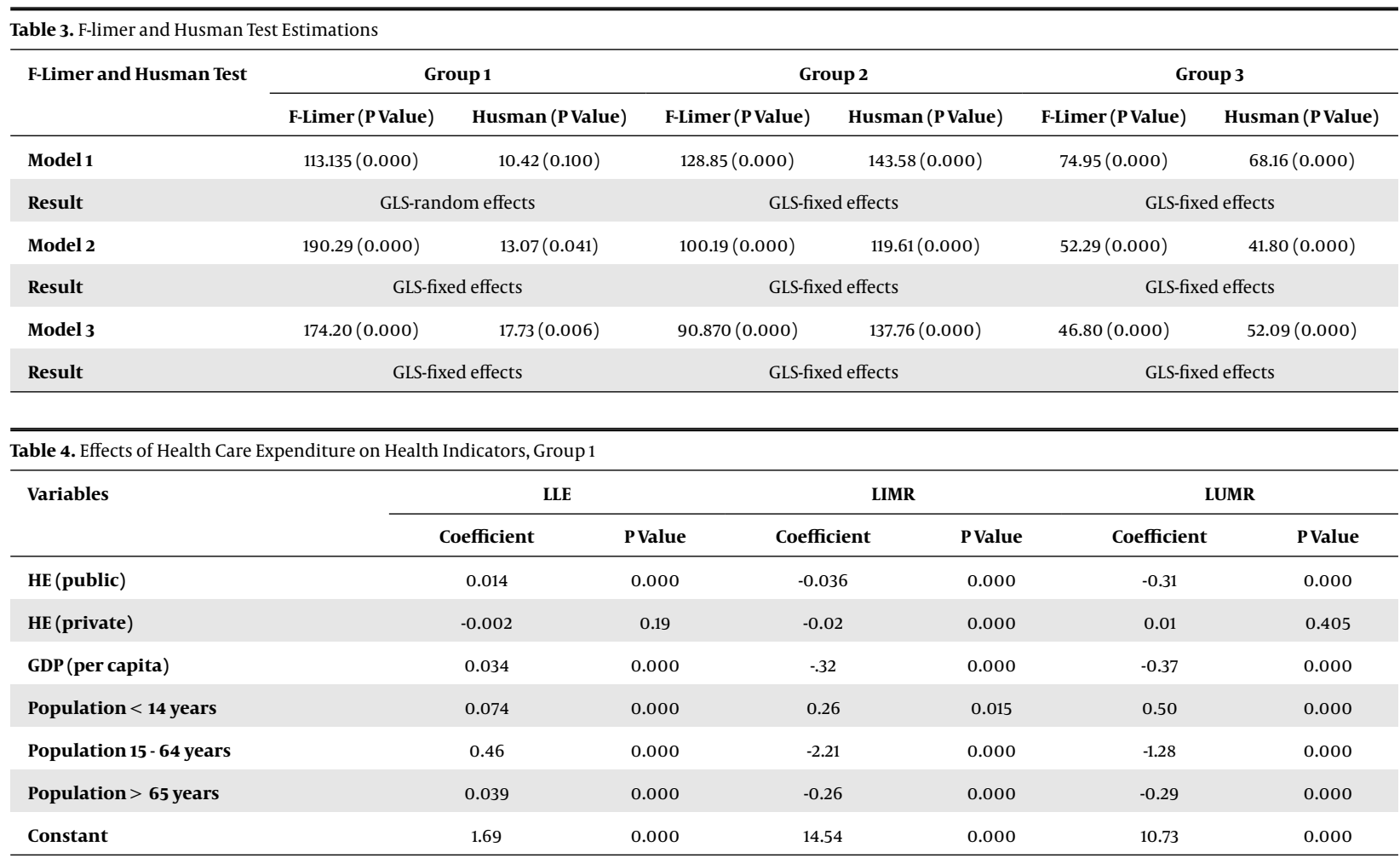

Abbreviations: LIMR, log infant mortality rate; LLE, log life expectancy; LUMR, under 5 mortality rate.

Table 5. Effects of Health Care Expenditure on Health Indicators, Group 2

\begin{tabular}{|c|c|c|c|c|c|c|}
\hline \multirow[t]{2}{*}{ Variables } & \multicolumn{2}{|c|}{ LLE } & \multicolumn{2}{|c|}{ LIMR } & \multicolumn{2}{|c|}{ LUMR } \\
\hline & Coefficient & P Value & Coefficient & P Value & Coefficient & PValue \\
\hline HE (public) & 0.003 & 0.021 & -0.043 & 0.004 & -0.053 & 0.000 \\
\hline HE (private) & 0.003 & 0.041 & 0.018 & 0.037 & 0.009 & 0.285 \\
\hline GDP (per capita) & 0.034 & 0.000 & -0.307 & 0.000 & -0.302 & 0.000 \\
\hline Population $<14, y$ & 0.017 & 0.347 & 1.137 & 0.000 & 0.989 & 0.000 \\
\hline Population 15 - 64, y & 0.063 & 0.145 & 1.269 & 0.000 & 0.863 & 0.014 \\
\hline Population $>65, y$ & 0.015 & 0.089 & -0.242 & 0.000 & -0.304 & 0.000 \\
\hline Constant & 3.639 & 0.000 & -3.110 & 0.117 & -0.672 & 0.736 \\
\hline
\end{tabular}

Abbreviations: LIMR, log infant mortality rate; LLE, log life expectancy; LUMR, under 5 mortality rate.

rate of public health expenditure and then in countries with the lowest rate of public health expenditure. However, in these two groups, private health expenditure did not have any significant effect on life expectancy. In the second group, which had the lowest effect of public health expenditure, private health expenditure had a positive effect on life expectancy too.

These results are consistent with several researchers including the study by Panahi and Aleemran, which showed a appositive effect of health expenditure on life expectancy (23), and also a study by Novignon et al., which indicated that private and public health expenditures have a positive effect on life expectancy (20).

Jaba reported that the total health expenditure causes an increase in life expectancy. In other words, the highest effect was observed in countries with incomes lower than average and the lowest effect was observed in countries with the highest income level. Moreover, due to geographical classification, the highest effects of health expenditure are observed in countries located in Eastern Asia, and the lowest effects are seen in European countries (10).

The Linden and Ray study in OECD countries revealed 


\begin{tabular}{|c|c|c|c|c|c|c|}
\hline \multirow[t]{2}{*}{ Variables } & \multicolumn{2}{|c|}{ LLE } & \multicolumn{2}{|c|}{ LIMR } & \multicolumn{2}{|c|}{ LUMR } \\
\hline & Coefficient & P Value & Coefficient & PValue & Coefficient & P Value \\
\hline HE (public) & 0.016 & 0.000 & -0.054 & 0.035 & -0.08 & 0.002 \\
\hline HE (private) & 0.003 & 0.158 & 0.024 & 0.137 & 0.038 & 0.014 \\
\hline Population $<14, y$ & -0.040 & 0.038 & 0.674 & 0.001 & 0.512 & 0.010 \\
\hline Population 15 - 64, y & -0.039 & 0.451 & -0.288 & 0.570 & 0.486 & 0.372 \\
\hline Population $>65, y$ & 0.036 & 0.003 & -0.743 & 0.000 & 0.794 & 0.000 \\
\hline Constant & 4.514 & 0.000 & 2.890 & 0.323 & 4.546 & 0.139 \\
\hline
\end{tabular}

Abbreviations: LIMR, log infant mortality rate; LLE, log life expectancy; LUMR, under 5 mortality rate.

that the relationship between health expenditure and health outcomes in different groups is not equal. That's to say, in the higher health expenditure groups and public and private expenditure have a positive effect on life expectancy, however, these effects become less in lower groups, and private expenditure effects even turn negative. These issues, of course, can be related to the different aims of public and private health expenditure (15). Health expenditure usually increases life expectancy with heterogeneity effects; specifically, it has more effect on the countries with lower life expectancy (5).

In this study, public health expenditure had significant effects on mortality rate in all groups. Therefore, in groups with a higher share of public health expenditure, a greater impact on infant mortality was observed, however, in regards to the under-five mortality rate, it was contrary. Nonetheless, the effect of private health expenditure was different; in the first group, including countries with the lowest rate of public health expenditure, it decreased the infant mortality rate, in the second group, infant mortality rate was increased, and in the third group, private health expenditure increased the under-five mortality rate. In other cases, no significant effect was observed.

In line with the current study's results, Novignon et al. reported that increasing the health expenditure will decrease the total mortality rate as well as the infant mortality rate. Moreover, the effects of public health expenditure are more than the effects of private health expenditure (20). Barenberg study's in India showed that public health expenditure has a large significant effect on the reduction of infant mortality rate (24)

In addition, a study by Arthur and Oaikhenan indicated that the total health expenditure causes a significant effect in reducing infant and under-five mortality rate; this reduction was significantly influenced by public health expenditure because of more investment in mortality reducing technology (25). However, the results of a study conducted by Akinlo and Sulola, with a different time period and model, revealed that public health expenditure has a positive effect on under-five and infant mortality and increase them. However, total health expenditure decreases the mortality rate. Perhaps this happened because of the high level of corruption and fungibility of public health expenditure in sub-Saharan Africa countries (18). Another study carried out in the European Union revealed that there is no statistically significant relationship between total health expenditure and total mortality rate (26).

Evidence regarding the effects of health expenditure on health outputs including life expectancy and mortality rate is complicated $(5,16,18)$. However, the majority of the studies indicate the positive effects of health expenditure on health outputs $(13,20,23,25)$.

As indicated in the current study; it seems that increasing the health expenditure, especially public health expenditure, well develops health facilities and improve the functions of health systems (20). Although increasing the level of public health expenditure can improve health status (15), this increase should not have adverse effects on an individual's health. In other words, such increases should not lead to an increase in taxes and costs of the consumers (7). Therefore, in order to prevent wasting health resources, policymakers should focus on improving management, efficient health programs benefiting from experienced managers, efficient allocation, providing an appropriate and efficient supervision on the implementation of the programs and the budgets, and analysis of efficient costs should be preceded the health policies $(7,18-20,26)$.

On the other hand, health policies that focus only on health services, family improvement program, and emergency cases cannot be efficient enough regarding the society's healthiest, if it ignores the practicality of the services and the socio-economic dimensions of its programs (7). In addition, the society expects the government to have an effective intervention in the health section in a way that health services become more available, people be protected against various issues endangering their health, and the poor be supported by the government (6). Therefore, effective health insurance schemes can be useful (25). 
Although there is a positive effect of public health expenditure on health indexes, as reported in the current study, some other factors affecting health improvement should not be ignored such as good nourishment, health oriented life habits (15), and social protection, which can also help to improve society's health and life expectancy (16). Moreover, the role of government is of considerable significance in a way that good governance can lead to better management of the health expenditure and a decrease in the mortality rate; the quality of the bureaucracy and corruption falls are among the other effective factors affecting the health indexes in a society. However, poorly governed countries did not show such significant effects (27).

\subsection{Limitation}

In this study, we investigated the effect of health expenditure on the indexes including life expectancy at birth, infant mortality rate, and under-five mortality rate. Consider other factors such as social protection, environment condition, individual life style, and economic changes can help have a better vision. In addition, our source data was World Bank and the last update for health expenditure by public and private, as the main variable was 2015 .

\subsection{Conclusions}

Since the provision of health services for individuals is of great social significance and benefit, health is located in the classification of a society's merit wants. If private sections want to provide a society's merit wants, the productions and services will be lower than the optimal level. In order to reach the optimal level, it is necessary for the government to intervene and provide the required financial resources. That is why it is expected that the efficiency of public health expenditure is much better than that of private health expenditure. Results of the current study also confirm such claims; according to these findings, public health expenditure had significant effects on health indicators in all groups. These expenditures increased life expectancy level and decreased the infants and under-five mortality rate in all group.

\section{Acknowledgments}

The authors would like to sincerely thank Iran University of Medical Sciences and those playing a role in conducting the current research by providing support and assistance.

\section{Footnotes}

Authors' Contribution: Study design: Aziz Rezapour, Abdoreza Mousavi, and Farhad Lotfi. Data collection: Samira Alipour. Data analysis: Abdoreza Mousavi and
Maryam Soleimani Movahed. Writing and editing of the manuscript and preparing the draft of report: Abdoreza Mousavi, Samira Alipour, and Aziz Rezapour. All authors approved the final version of the manuscript.

Conflict of Interests: There is no conflict of interest to be declared.

Ethical Approval: This study was approved by the Ethics Committee of School of Health Management and Information Sciences of Iran University of Medical Sciences (IR.IUMS.REC1395.9411552009).

Funding/Support: This study is part of a master's thesis with a code of ethics (IR.IUMS.REC1395.9411552009) that was supported by the School of Health Management and Information Sciences of Iran University of Medical Sciences.

\section{References}

1. Tikunov VS, Chereshnya OY. Public health index in Russian Federation from 1990 to 2012. Soc Indic Res. 2015;129(2):775-86. doi: 10.1007/s11205015-1144-x.

2. Tapia Granados JA, Ionides EL. Mortality and macroeconomic fluctuations in contemporary Sweden. Eur J Popul. 2011;27(2):157-84. doi: 10.1007/s10680-011-9231-4.

3. Ketenci N, Murthy VNR. Some determinants of life expectancy in the United States: Results from cointegration tests under structural breaks. J Econ Finance. 2017;42(3):508-25. doi: 10.1007/s12197-017-94012 .

4. Tapia Granados JA. Economic growth and health progress in England and Wales: 160 years of a changing relation. Soc Sci Med. 2012;74(5):688-95. doi: 10.1016/j.socscimed.2011.11.019. [PubMed: 22285290].

5. Obrizan M, Wehby GL. Health expenditures and global inequalities in longevity. World Dev. 2018;101:28-36. doi: 10.1016/j.worlddev.2017.08.003.

6. Nandakumar AK, Farag ME. Determinants of national health expenditure. International Encyclopedia of Public Health. 2008. p.136-45. doi: 10.1016/b978-012373960-5.00171-4.

7. Fayissa B, Gutema P. Estimating a health production function for Sub-Saharan Africa (SSA). Appl Econ. 2005;37(2):155-64. doi: 10.1080/00036840412331313521.

8. Narayan PK. Modelling health and output at business cycle horizons for the USA. Health Econ. 2010;19(7):872-80. doi:10.1002/hec.1524. [PubMed: 19582696].

9. Blazquez-Fernández C, Cantarero-Prieto D, Pascual-Saez M. Is pharmaceutical expenditure related to the business cycles? Appl Econ Lett 2015;23(10):705-7. doi: 10.1080/13504851.2015.1102834.

10. Jaba E, Balan CB, Robu IB. The relationship between life expectancy at birth and health expenditures estimated by a cross-country and time-series analysis. J Econ Finance. 2014;15:108-14. doi: 10.1016/s22125671(14)00454-7.

11. Mackenbach JP, Looman CW. Life expectancy and national income in Europe, 1900-2008: An update of Preston's analysis. Int J Epidemiol. 2013;42(4):1100-10. doi: 10.1093/ije/dyt122. [PubMed: 23920140].

12. Getzen TE. Macroeconomic dynamics of health: lags and variability in mortality, employment and spending. 2011.

13. Raeesi P, Harati-Khalilabad T, Rezapour A, Azari S, Javan-Noughabi J. Effects of private and public health expenditure on health outcomes among countries with different health care systems: 2000 and 2014. Med J Islam Repub Iran. 2018;32:35. doi: 10.14196/mjiri.32.35. [PubMed: 30159286]. [PubMed Central: PMC6108280].

14. Braendle T, Colombier C. What drives public health care expenditure growth? Evidence from Swiss cantons, 1970-2012. Health Policy. 
2016;120(9):1051-60. doi: 10.1016/j.healthpol.2016.07.009. [PubMed: 27496155].

15. Linden M, Ray D. Life expectancy effects of public and private health expenditures in OECD countries 1970-2012: Panel time series approach. Econ Anal Policy. 2017;56:101-13. doi:10.1016/j.eap.2017.06.005.

16. van den Heuvel WJ, Olaroiu M. How important are health care expenditures for life expectancy? A comparative, European analysis. J Am Med Dir Assoc. 2017;18(3):276 e9-276 e12. doi 10.1016/j.jamda.2016.11.027. [PubMed: 28131720].

17. Rezapour A, Mousavi A, Soleymani MM. [The impact of business cycles on life expectancy in countries of the Iran vision plan 2025].J Health care Manage. 2018;9(2):7-17. Persian.

18. Akinlo AE, Sulola AO. Health care expenditure and infant mor tality in sub-Saharan Africa. J Policy Model. 2019;41(1):168-78. doi: 10.1016/j.jpolmod.2018.09.001.

19. Blazquez-Fernández C, Cantarero-Prieto D, Pascual-Saez M. Health expenditure and socio-economic determinants of life expectancy in the OECD Asia/Pacific area countries. Appl Econ Lett. 2016;24(3):167-9. doi 10.1080/13504851.2016.1173174.

20. Novignon J, Olakojo SA, Nonvignon J. The effects of public and private health care expenditure on health status in sub-Saharan Africa: New evidence from panel data analysis. Health Econ Rev. 2012;2(1):22 doi: 10.1186/2191-1991-2-22. [PubMed: 23232089]. [PubMed Central:
PMC3533939].

21. World Health Organization. Global Health Expenditure databas. 2019. Available from: http://apps.who.int/nha/database.

22. Bidirici M, Bohur E. Design and economic growth: Panel cointegration and causality analysis. Procedia Soc Behav Sci. 2015;210:193-202. doi: 10.1016/j.sbspro.2015.11.359.

23. Panahi H, Aleemran SA. [The effect of inflation, health expenditure and urbanization on life expectancy in the Middle E ast and North Africa Countries (MENA)]. J Iran Inst Health Sci Res. 2016;15(4):346-51. Persian.

24. Barenberg AJ, Basu D, Soylu C. The effect of public health expenditure on infant mortality: Evidence from a panel of Indian States, 1983-1984 to 2011-2012. J Dev Studies. 2016;53(10):1765-84. doi: 10.1080/00220388.2016.1241384.

25. Arthur E, Oaikhenan HE. The effects of health expenditure on health outcomes in sub-Saharan Africa (SSA). Afr Dev Rev. 2017;29(3):524-36. doi: 10.1111/1467-8268.12287.

26. Lippi G, Mattiuzzi C, Cervellin G. No correlation between health care expenditure and mortality in the European Union. Eur J Intern Med. 2016;32:e13-4. doi: 10.1016/j.ejim.2016.02.025. [PubMed: 26987418].

27. Rajkumar AS, Swaroop V. Public spending and outcomes: Does governance matter? J Dev Econ. 2008;86(1):96-111. doi: 10.1016/j.jdeveco.2007.08.003. 